\title{
ROLE OF CONVENTIONAL PLAIN X-RAYS IN UPPER AERODIGESTIVE TRACT FISH BONE IMPACTION
}

\section{Kamran Zamurrad Malik', Usman Rafique ${ }^{2}$, Shahzad Nayyar ${ }^{1 \otimes}$, Tehniat Ghias'}

\begin{abstract}
OBJECTIVE: To assess the role of conventional plain $X$-rays in managing fish bone impaction in throat, after eating commonly consumed species of fish in Pakistan.

METHODS: This cross-sectional descriptive study was conducted at Combined Military Hospital Muzaffarabad, Pakistan. X-ray of bones from eight different species of commonly eaten fish were taken (in-vitro) and then compared to X-ray of same bone kept in oral cavity of a volunteer (in-vivo), in order to assess the effect of soft tissue and bony super imposition on radio opacity of fish bone and its clinical impact. The radiographs were taken using Siemens 500 MAS machine with an exposure of $65 \mathrm{kV}$ for adults. Both the in vitro and in vivo radiographs were reviewed by thirty doctors of varied echelons ranging from interns to consultants of varying specialties (ENT, Radiology, Internal Medicine, General Surgery).
\end{abstract}

RESULTS: Bones of seven fish species were $100 \%$ identified on in- vitro film while one fish type (drum fish) was identified by $93.3 \%(n=28 / 30)$ observers. Whereas, in-vivo identification of same bones ranged from $0.00 \%$ to a maximum of $33.33 \%$. On in-vivo films, the maximally visualized fish bones were Mahseer and Butter fish ( $n=10 / 30 ; 33.3 \%$ each) followed by Catla/Indian carp, Eel, Pomfret and Cobia ( $n=5 / 30 ; 16.6 \%$ each). Croaker/drum fish could not be visualized by any observer on in-vivo films.

CONCLUSION: Conventional plain $\mathrm{X}$-rays alone cannot be relied upon for diagnosing fish bone impaction in upper aero-digestive tract.

KEY WORDS: X-Rays (MeSH), Conventional X-rays (Non-MeSH), Fishes $(\mathrm{MeSH})$, Fish bone (Non-MeSH), Foreign bodies (MeSH), Impaction (Non$\mathrm{MeSH})$.

THIS ARTICLE MAY BE CITED AS: Malik KZ, Rafique U, Nayyar S, Ghias T. Role of conventional plain $\mathrm{x}$ - rays in upper aerodigestive tract fish bone impaction. Khyber Med Univ J 202I;13(1):36-9. DOI: https://doi.org/ I0.35845/kmuj.2021.20162.

\section{INTRODUCTION}

5 oreign body impaction is not uncommon and carries significant morbidity and mortality.' Fish and chicken bones comprise the majority of impacted foreign bodies in adults. ${ }^{2,3}$ In case of impaction, the patient usually experiences sharp pain after taking the bolus and develops odynophagia. ${ }^{4}$ The commonest sites of impaction in descending frequency are tonsil, tongue base, pyriform sinus and vallecullae, however, rarely it can get impacted in esophagus. ${ }^{4,5}$ If an impacted fish bone is not removed it can result in serious complications like mediastinitis, retro and parapharyngeal abcesses and rarely oesophago-aortic fistula, all of which can have fatal eventuality. In addition, neglecting an impacted fish bone can cause its migration and can present as neck abscess, as a foreign body in thyroid gland and rarely pierce the tracheal wall to present as foreign body airway. ${ }^{6-8}$

Impacted fish bones in most of cases are retrieved after direct visualization, mirror or fiberoptic nasoendoscopic examination. 9.10 In cases where the above methods fail endoscopy is resorted to which is the gold standard both in diagnosis and removal of impacted fish bone." Endoscopy requires specialist intervention therefore lateral view $\mathrm{x}$-ray of neck for soft tissue is frequently requested for localization before specialist referral." However, it
I: Combined Military Hospital (CMH), Muzaffarabad, Pakistan.

2: CMH Murree, Pakistan. Email凹: shez.nyr@gmail.com Cell \# +92-333-5659565

Date Submitted: September 25, 2020

Date Revised: February 20, 2021

Date Accepted: March 03, 2021

is a common practice in emergency departments to request for neck $\mathrm{x}$-rays if fishbone is not visualized on torch examination of oral cavity which unnecessarily burdens the radiology departments and consumes already meager resources.

Fruitful outcome of plain x-rays is not always guaranteed as its sensitivity for detection of upper aerodigestive tract fishbone impaction is graded as poor due to presence of high soft tissue and bony density. ${ }^{10-12}$ This is diagnostic in only one third of patients due to relative less radiodensity of fish bone in comparison to surrounding structures while yields false positive impressions in one third cases due to calcification of laryngeal cartilages specially in older patients. ${ }^{2,11}$ This false positive $x$-ray occasionally becomes a sore point in doctor-patient relationship as patients and attendants take calcified cartilages as foreign body and relate their present and future symptoms to fish bone impaction no matter how painstakingly prolonged counseling is done by specialists regarding the absence of fish bone. The same false positive results can result in unnecessary surgical interventions if wrongly interpreted by the treating physicians. The false negative x-ray can result in missed diagnosis and can harbor catastrophic outcomes. ${ }^{5-8}$ The deciding variable of fish bone visibility on $\mathrm{x}$-ray is its radio density which is dependent upon the habitat and functional anatomy, made evident by more radio density of surface dwelling fish like cod as compared to deep-sea fish., 912

The type of fish eaten in our area is different from most of the countries where such studies were carried out so a dire need was felt to carry out this 
TABLE I: COMPARISON OF VARIOUS FISH BONE DETECTION IN RADIOGRAPHS BY OBSERVERS

\begin{tabular}{|c|l|l|c|c|}
\hline No & $\begin{array}{c}\text { Local } \\
\text { name }\end{array}$ & $\begin{array}{c}\text { Common } \\
\text { English name }\end{array}$ & $\begin{array}{c}\text { In-vitro radiograph } \\
\text { identification of fish } \\
\text { bone by observers } \\
\mathbf{( n = 3 0 )}\end{array}$ & $\begin{array}{c}\text { In-vivo radiograph } \\
\text { identification of fish } \\
\text { bone by observers } \\
(\mathbf{n}=\mathbf{3 0})\end{array}$ \\
\hline I. & Mahasher & Mahseer & $30 / 30(100 \%)$ & $10 / 30(33.3 \%)$ \\
\hline 2. & Rahu & Butter fish & $30 / 30(100 \%)$ & $10 / 30(33.3 \%)$ \\
\hline 3. & Thaila & Catla/ Indian carp & $30 / 30(100 \%)$ & $5 / 30(16.6 \%)$ \\
\hline 4. & Bam & Eel & $30 / 30(100 \%)$ & $5 / 30(16.6 \%)$ \\
\hline 5. & Paplate & Pomfret & $30 / 30(100 \%)$ & $5 / 30(16.6 \%)$ \\
\hline 6. & Singhara & Cobia & $30 / 30(100 \%)$ & $5 / 30(16.6 \%)$ \\
\hline 7. & Silver & Silver carp & $30 / 30(100 \%)$ & $0 / 30(0.0 \%)$ \\
\hline 8. & Mushka & Croaker /drum & $28 / 30(93.3 \%)$ & $0 / 30(0.0 \%)$ \\
\hline
\end{tabular}

study in order to justify the utility of this diagnostic radiological investigation in our setups. As there is limited research on types of fish available in Pakistan, ${ }^{13,14}$ we planned this study to assess the role of conventional plain $x$-ray in upper aerodigestive tract fish bone impaction of commonly eaten fish in Pakistan.

\section{METHODS}

The study was conducted at Department of Ear Nose and Throat in at Combined Military Hospital Muzaffarabad Pakistan, after taking permission from hospital ethical committee. It was a cross-sectional descriptive study and technique of convenience purpose sampling was utilized. Cooked samples of eight most utilized fish species i.e Thaila (Catla/ Indian carp), Bam (Eel), Silver (silver carp), Paplate (Pomfret), Mahasher (Mahseer), Rahu (Butter Fish), Singhara (Cobia) and Mushka (Croaker/drum) were bought from local fish market. Bones were removed from the meat and washed. Identification markers were placed (I. Thaila, 2. Bam, 3. Silver, 4. Paplate, Mahasher, 5. Rahu, 6. Singhara and 8. Mushka), and conventional radiographs of fish bones were taken, which was referred as in vitro in the study. Then the fish bones were kept in the oral cavity of volunteers (Buccogingival sulcus) and a lateral $\mathrm{x}$-ray neck for soft tissues was taken. The volunteers included patients undergoing neck $X$-rays for other reasons e.g. cervical spine or nasopharyngeal assessment. Informed consent was obtained. The radiographs were taken using Siemens 500 MAS machine with an exposure of $65 \mathrm{kV}$ for adults. These radiographs were referred as in vivo in the study. Both the in vitro and in vivo radiographs were reviewed by thirty doctors of varied echelons ranging from interns to consultants of varying specialties (ENT, Radiology, Internal medicine, general surgery). These specialties were chosen as they were involved in initial first aid care and early management of these cases in ER or OPD. The response was recorded as either positive or negative for fish bone.

\section{RESULTS}

In this study, $x$-rays were observed by 30 doctors including $9(30 \%)$ specialists and 21 (70\%) residents. Bones of seven fish species were $100 \%$ identified on invitro film while one fish type (drum fish) was identified by $93.3 \% \quad(n=28 / 30)$ observers. In vivo identification of same bones ranged from $0.00 \%$ to a maximum of $33.33 \%$ (Table I). The combined sensitivity of in vitro study was $99.17 \%(n=238 / 240)$ whereas the combined sensitivity of in vivo study was $16.67 \%(n=40 / 240)$. On in vivo films, the maximally visualized fish bones were Mahseer and Butter Fish $(n=10 / 30$; $33.3 \%$ each), while bones of Silver carp and Croaker could not be identified by any observer in in vivo study.

\section{DISCUSSION}

In our study. Sensitivity of fish bone identification on conventional X-rays was $99.17 \%$ \& $16.67 \%$ for in vitro and in vivo radiographic evaluation respectively. On in vivo films, the maximally visualized fish bones were Mahseer and Butter fish while bones of Silver carp and Croaker could not be identified by any observer in in vivo study.

The most commonly encountered foreign body in throat region, whether
Emergency department or ENT OPD is the fish bone. ${ }^{15,16}$ The literature shows paucity in studies aimed at efficacy of $x$ rays in fish bone detection. Different studies revealed a poor sensitivity of $x-$ rays in detection of fish bones impacted in aerodigestive tract. Sensitivities of $32 \%, 29 \%$ and $25 \%$ were demonstrated by studies and could be attributed to the density of fish bone. ${ }^{12,17,18}$ Our study conforms to these studies demonstrating even lower sensitivity of the x-ray in detecting fish bone. The relatively more sensitivity of Mahseer and Butter Fish (33.3\%) in our study may be attributed to difference in mineralization of bones." This difference in radiodensity of different species of fish has also been demonstrated by other studies, however, they utilized ovine or head and neck phantoms for the study rather than in vivo radiographs. ${ }^{5,9,11}$

While the X-ray may be unable to detect impacted fish bones, it is widely accepted that a negative $x$-ray cannot be relied upon to rule out the impacted fish bone. ${ }^{12,17-19}$ Regardless of the outcome of $\mathrm{x}$-rays, a detailed oral examination which may or may not be followed by mirror examination or fibreoptic nasolaryngoscopy has been advocated by most authors. ${ }^{10,17,18}$ Although it has been argued that $\mathrm{x}$-ray lateral tissue of neck is requested not only to see the impacted fish bone but also the radiological signs which are associated with impacted foreign body. However, these signs (soft tissue swelling, presence of air in soft tissue or in esophagus) usually take some time i.e 312 hours to develop and be visualized on $\mathrm{x}$-ray and usually patients are seen in emergency much earlier..$^{0,20}$ The presence of thick soft tissue and dense bones of upper aerodigestive tract make the detection of fishbone against the radio dense background difficult. ${ }^{10}$ Pyriform fossae ,larynx, cricopharyngeus, cervical and thoracic oesophagus are less frequent sites of fish bone impaction " and radiological detection at these sites may be more difficult owing to ossification of cricoid, thyroid and other laryngeal cartilages.

Both the false positive and false negative $x$-rays can have significantly grave implications in terms of missed 
diagnosis leading to complications and undue surgical interventions. Theoretically it is possible that the portions of bones impacted in high tissue density regions may traverse to low tissue density regions and may become radiologically visible but to pick this up by physicians working in emergency departments who are neither trained in radiology nor in otolaryngology is very unlikely." One of the studies has shown that fish bone, be it raw or cooked, fresh water or sea water, can be identified with digital radiography, a fact comparable to our in vitro results but they had used a soft tissue phantom rather than human body therefore the impact of their results in in vivo settings cannot be relied upon. Even in studies carried out locally, $x$-rays could not be identified as a reliable source to detect fish bone impaction in aerodigestive tract. ${ }^{14}$

CT scan has been shown to have $100 \%$ sensitivity and specificity in detection of either impacted fish bone or signs associated with impaction ${ }^{10,21,22}$, but the cost, time consumption and availability of facility limits its usage.

\section{Limitations}

Certain problems were encountered during this study that needs to be elaborated.

a. The size of fish bone that the patients present with is much smaller as compared to one used in study which will make detection even on in vitro $\mathrm{x}$-rays more difficult.

b. The current study was conducted in a small sample. The larger sample size utilizing all the species eaten in Pakistan will be more beneficial.

\section{CONCLUSION}

Conventional $\mathrm{X}$-rays showed very low sensitivity for in vivo radiographic evaluation of fish bone identification, especially for Silver carp and Croaker. Fish bone impaction is not an uncommon problem and most of the fish bones of commonly eaten fish are not visible on lateral neck $\mathrm{x}$-rays so more emphasis should be made on thorough ENT examination and utilizing fiberoptic nasopharyngoscopy. Xrays should only be resorted to in cases of negative clinical examination and positive history before being planned for formal endoscopy that too is surpassed by CT scan if available.

\section{REFERENCES}

I. Prakash A RB, Rais P, Baskota D, Sinha B. Role of plain xray soft tissue neck lateral view in the diagnosis of cervical esophageal foreign bodies. Internet J Otorhinolaryngol 2008;8(2): I-5.

2. Devarajan K, Voigt S, Shroff S, Weiner SG, Wein RO. Diagnosing fish bone and chicken bone impactions in the emergency department setting: measuring the system utility of the plain film screen. Ann Otol Rhinol Laryngol 2015 Aug;|24(8):6|4-2I. DOI: |0.1|77/00034894|5573072.

3. Puthumanakunnel AM, George S. Clinical presentation and treatment outcome in patients presenting with foreign body in ear, nose and throata three-year tertiary hospital experience. J Evol Med Dent Sci 20I8;7(2):|46-8. DOI: I0.14260/ jemds/2018/32.

4. Kumar S, Yu C, Toppi J, Ng M, Hill F, Sist N. The Utility of Diagnostic Imaging in Fish Bone Impaction. Open J Radiol 2018;8(0I):45. DOI: 10.4236/ojrad.2018.81006.

5. Davies WR, Bate PJ. Relative radioopacity of commonly consumed fish species in South East Queensland on lateral neck $x$-ray: an ovine model. Med J Aust 2009 Dec 7-21; 191(III2):677-80. DOI: $10.5694 / \mathrm{j} .1326$ 5377.2009.tb03378.x.

6. Chiluveru P, Kumar A, Chavadaki J. Migratory fish bone complicating as neck abscess. Int J Otorhinolaryngol Head Neck Surg 20 18;4(2):588-90. DOI: $10.18203 /$ issn.2454-5929. ijohns20I80732.

7. Mohamad A, Ahmad MZ, Mohamad I. A piercing fish bone through tracheal wall. Int J Hum Health Sci. 20I8;2(I):35-7.

8. Wu E, Huang L, Zhou Y, Zhu X Migratory Fish Bone in the Thyroid Gland: Case Report and Literature Review. Case Rep Med 2018 Feb
22;2018:7345723. DOI: 10.1155/ $2018 / 7345723$.

9. Shetty D, Gay DA. The lateral neck radiograph for an impacted fish bone in the aero-digestive tract: Going back to basics. J Biomed Sci Eng 20I2;5(I 2):826-8. DOI: |0.4236/jbise.20 | 2.5 | 2A I 04 .

I0. Sanei-Moghaddam A, SaneiMoghaddam A, Kahrobaei S. Lateral soft tissue $X$-ray for patients with suspected fishbone in oropharynx, A thing in the past. Iran J Otorhinolaryngol 2015;27(83):459-62.

I I. Ritchie T, Harvey M. The utility of plain radiography in assessment of upper aerodigestive tract fishbone impaction: an evaluation of $22 \mathrm{New}$ Zealand fish species. N Z Med J (Online) 20I 0; I 23(I3 I3): 32-7.

12. Evans R, Ahuja A, Williams SR, Van Hasselt $C$. The lateral neck radiograph in suspected impacted fish bonesdoes it have a role? Clin Radiol 1992 Aug;46(2):I2I-3. DOI: 10.1016/s0009-9260(05)80316-2.

13. Kundi NA, Mehmood TJPAFMJ. Diagnostic accuracy of indirect laryngoscopy and x-ray neck in the diagnosis of fish bone impaction in upper aero digestive tract. Pak Armed Forces Med J 2015;65(2): 216-20.

14. Qureshi TA, Awan MS, Hussain M, Wasif M. Effectiveness of plain X-ray in detection of fish and chicken bone foreign body in upper aerodigestive tract. J Pak Med Assoc 2017;67(4): 544-7.

15. Huang Z, Li P, Xie L, Li J, Zhou H, Li Q. Related factors of outcomes of pharyngeal foreign bodies in children. SAGE Open Med 2017;5:20503 I 2 I I7724057. DOI: |0.1|77/20503|2|17724057.

16. Watanabe K, Amano M, Nakanome A, Saito D, Hashimoto S. The prolonged presence of a fish bone in the neck. Tohoku J Exp Med 2012 May;227(I):49-52. DOI: 10.1620/ tjem.227.49.

17. Sundgren PC, Burnett A, Maly PV. Value of radiography in the management of possible fishbone 
ingestion. Ann Otol Rhinol Laryngol 1994 Aug; I03(8 Pt I):628-3I. DOI: 10.1177/000348949410300809.

18. Ngan JH, Fok PJ, Lai EC, Branicki FJ, Wong J. A prospective study on fish bone ingestion. Experience of 358 patients. Ann Surg 1990 Apr;2 I I (4): 459-62. DOI: 10.1097/00000658$199004000-00012$.

19. Lue AJ, Fang WD, Manolidis S. Use of plain radiography and computed tomography to identify fish bone foreign bodies. Otolaryngol Head Neck Surg 2000 Oct; I 23(4):435-8. DOI: 10.1067/mhn.2000.99663.

20. Knight L, Lesser T. Fish bones in the throat. Arch Emerg Med 1989 Mar;6(I):|3-6. DOI: 10.1136/ emj.6.I.I3.

21. Akazawa Y, Watanabe S, Nobukiyo S, Iwatake H, Seki Y, Umehara T, et al. The management of possible fishbone ingestion. Auris Nasus Larynx 2004 Dec;3 I (4):4 I 3-6. DOI: I0.1016/j.anl.2004.09.007.

22. Watanabe K, Kikuchi T, Katori Y, Fujiwara $H$, Sugita $R$, Takasaka $T$, et al. The usefulness of computed tomography in the diagnosis of impacted fish bones in the oesophagus. J Laryngol Otol 1998 Apr; II2(4):360-4. DOI: 10.1017/ s00222I5I00140460.

\section{AUTHOR'S CONTRIBUTION}

Following authors have made substantial contributions to the manuscript as under:

KZK: Conception and study design, acquisition of data, drafting the manuscript, critical review, approval of the final version to be published

UR: Acquisition of data, drafting the manuscript, approval of the final version to be published

SN: Analysis and interpretation of data, drafting the manuscript, approval of the final version to be published

TG: Acquisition, analysis and interpretation of data, critical review, approval of the final version to be published

Authors agree to be accountable for all aspects of the work in ensuring that questions related to the accuracy or integrity of any part of the work are appropriately investigated and resolved.

CONFLICT OF INTEREST
Authors declared no conflict of interest
GRANT SUPPORT AND FINANCIAL DISCLOSURE
Authors have declared no specific grant for this research from any
funding agency in the public, commercial or not-for-profit sectors

\section{DATA SHARING STATEMENT}

The data that support the findings of this study are available from the corresponding author upon reasonable request.

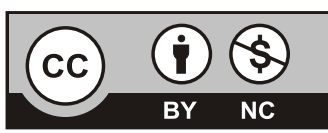

This is an Open Access article distributed under the terms of the Creative Commons Attribution-Non Commercial 2.0 Generic License.
KMUJ web address: www.kmuj.kmu.edu.pk

Email address: kmuj@kmu.edu.pk 